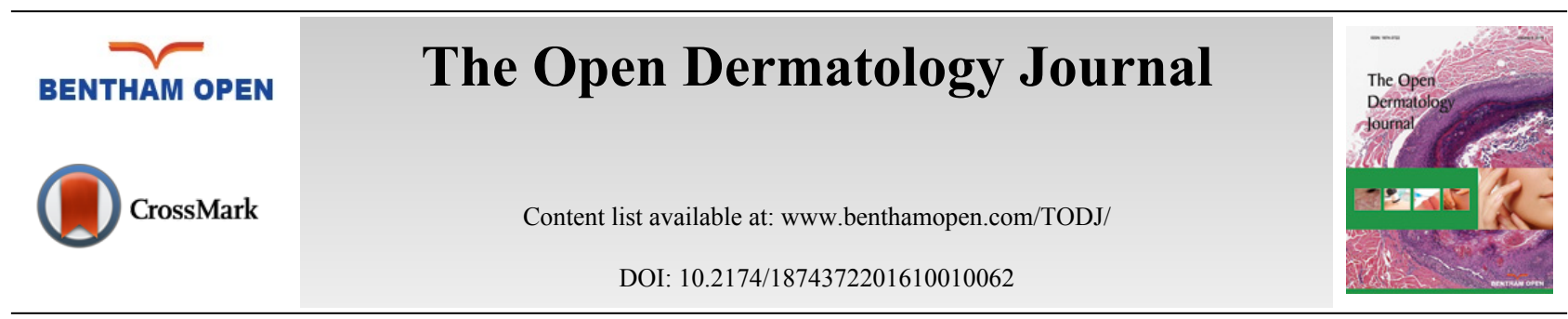

\title{
Diagnostic Tools for Borrelia Assessment in Humans
}

\author{
Serena Bonin* \\ Department of Medical Sciences, Unit of Dermatology, University of Trieste, Trieste, Italy
}

\begin{abstract}
Although the etiological agent of Lyme disease has been known since 1980s, diagnosis of Lyme disease is still a controversial topic because of the wide range of clinical manifestations and the limited diagnostic tools available to assess Borrelia in humans.

The most used diagnostic tool for Lyme disease is currently serology, but also Polymerase chain reaction (PCR) and other methods are often used to prove Borrelia infection in different patients' specimens. The present article deals with most of the diagnostic tools used in clinical practice for Lyme disease detection in human samples. Direct and indirect specific methods for Borrelia infection detection will be discussed.

The most recent peer reviewed publications as well as original results from our study and information provided by companies' web sites have been analyzed to compile this review article.
\end{abstract}

Keywords: Borrelia, commercial kits, PCR, serologic tests, standardization.

\section{BACKGROUND}

Although the etiological agent of Lyme disease has been known since 1980s, diagnosis of Lyme disease is still a controversial topic [1]. The medical community is divided into two groups: the first one recognizes that Lyme disease is associated with certain objective clinical manifestations supported by laboratory evidence of infection with Borrelia burgdorferi sensu lato, while the second one believes that Lyme disease patients may also present with aspecific symptoms without laboratory evidence in case of occult infections [1,2]. Except in cases with the pathognomonic clinical manifestation of erythema migrans, the diagnosis of Lyme borreliosis usually requires confirmation by means of a microbiological diagnostic assay [3]. Although the most informative tool for Borrelia detection is direct culture isolation from blood or other body tissues, this approach is unsuitable for diagnosis and its use is confined to particular situations. Indirect methods for Borrelia infection are thus preferred, and the main diagnostic tool for Lyme disease is nowadays serology, which is the only one approved by the FDA (Food and Drug Administration). Detection of Borrelia by culture isolation and nucleic acid techniques is confined to special situations, such as to clarify clinically and serologically ambiguous findings [3]. Recently, CE-IVD (European Community marked -in vitro Diagnostic Medical Devices) tests for Borrelia detection by PCR in clinical specimens have been produced [4 - 10], but none has been approved by the FDA. In the following sections both serologic and PCR techniques for Borrelia detection will be discussed.

Over the last decade non-specific tests have also been investigated for Lyme disease diagnosis; among them, CD57 cell count [11 - 13] and chemokine 13 level in cerebrospinal fluids [14 - 16] have been proposed with controversial results. It is not the aim of this study to report on aspecific detection methods, therefore those types of analyses will not be discussed hereafter.

\footnotetext{
* Address correspondence to this author at the Department of Medical Sciences, Unit of Dermatology, Cattinara Hospital Strada di Fiume 44734149 , Trieste, Italy; Tel +39 040 3996266; Fax: +39 040 360605; Email: sbonin@units.it
} 


\section{DIRECT DETECTION OF BORRELIA}

A variety of laboratory techniques have been developed for direct detection of B. burgdorferi sensu lato. Those assays provide evidence for the presence of intact spirochetes or spirochete components such as DNA or protein in tick vectors, reservoir hosts, or patients.

Four different approaches have been used in the clinical laboratory: microscope-based assays, detection of B. burgdorferi-specific proteins or nucleic acids, and culture [17].

\subsection{Culture}

Borrelia burgdorferi sensu lato can be cultivated from various tissues and body fluids in modified Kelly-Pettenkofer medium (MKP), Barbour-Stoenner-Kelly II (BSK-II) medium, and commercially available BSK-H medium [3, 18]. The yield of Borrelia culture from clinical samples is usually low with a higher rate of positivity from skin biopsy compared to blood and CSF cultures [18]. Borrelia cultivation and isolation is a time-consuming and demanding procedure. Successful cultivation can take up to 12 weeks [18]. In addition, preparation of culture media is demanding and expensive. Nonetheless, cultivation is the golden standard to prove the presence of active infection by Borrelia. Slow growth along with low clinical sensitivity $[17,19]$ do not make it a diagnostic tool for Lyme disease, and for this specific reason it will not be deeply considered in the present article.

\subsection{Microscopy}

Microscopic detection of Borrelia burgdorferi sensu lato has not been frequently used in clinical practice for confirmation of Lyme disease, mostly due to the sparseness of organisms in clinical samples [17]. Warthin-Starry stain, which consists of silver impregnation of microorganisms, was the oldest method used to search for Borrelia in histologic preparations in the 1990s, but recently only two publications have reported on the use of this stain for Borrelia detection [20, 21]. Among microscopic techniques focus floating microscopy (FFM), a modified immunohistochemical technique that combines several strategies to detect minuscule organisms in tissue sections, appears to be the most promising one for direct Borrelia detection, because it can be successfully applied on fresh material, nitrogen-frozen material, and paraffin-embedded tissues, in many cases on blocks older than 30 years [22]. Focus-floating microscopy has been recently proposed as the possible golden standard for detecting cutaneous borreliosis [22]. Not only a polyclonal antibody to Borrelia, a vivid chromogen (3-amino-9-ethylcarbazole) and the purposeful omission of counterstaining are necessary, but the technique also requires the histologist's patience [23]. By meticulously examining the entire slide horizontally and vertically, Eisendle et al. [22] have been able to find organisms with $98 \%$ sensitivity in classic examples of cutaneous borreliosis [22]. Since its first appearance in 2007 [22], FFM has been applied to several studies [21, 24 - 35], enabling detection of Borrelia and allowing that a number of dermatological conditions, such as morphea and lichen sclerosus et atrophicus, could be attributed to Lyme Borreliosis [28]. Unfortunately, although FFM is promising and helpful to prove Borrelia infection in cutaneous atypical lesions, only a few centers have adopted this technique.

\subsection{PCR}

Direct detection of Borrelia in clinical specimens is typically accomplished by PCR. Advantages of PCR are sensitivity, simplicity and speed [36]. A huge amount of articles have been published reporting on the use of PCR assays for Borrelia detection in human specimens, but large comparative studies aimed to identify the best PCR method are still lacking [3]. PCR assays differ in terms of target (borrelia sequence targeted by primers), PCR approach (nested PCR, real time PCR, PCR followed by hybridization...) as well as type of samples (blood, biopsies, cerebrospinal fluid, synovial fluid...) [37, 38]. Different types of PCR protocols could be applied for Borrelia detection, namely nested PCR, PCR followed by hybridization, realtime PCR, the latter both in qualitative as well as quantitative setting [37, 38]. Several and different protocols, mostly in house, are in use in most laboratories. Differences in protocols also rely on the type of samples and extraction procedures together with the broad range of clinical manifestations of Lyme disease. Different methods could be used to extract DNA and they could have different yields. Moreover, DNA extracts could be contaminated by PCR inhibitory substances due to poor extraction procedures [37]. Because of Borrelia paucity in biological liquids and tissues the diagnostic sensitivity of PCR was found to be low when using low volumes of sample material [3, 37]. As reported by Nolte PCR assays to detect Borrelia from CSF, synovial fluids or urines need large volumes for extraction in order to increase the sensitivity of the method [37]. Low and transient spirochetemia and high spirochoetes' tropism for tissues (joints, heart, meninges) may account for negative PCR results in blood and other 
biological fluids [38]. While PCR is highly sensitive for detection of B. burgdorferi sensu lato DNA in skin biopsy samples, such testing for patients with Lyme disease involving systems other than skin, has in general low sensitivity, with the exception of patients with Lyme arthritis [17]. PCR protocols for Borrelia detection have been developed by targeting plasmid as well as borrelial chromosome. The most frequent target for plasmid borrelial DNA is OspA which in some cases have also been used for Borrelia genotyping [36, 39 - 43]. Among chromosomal targets the most frequently assessed in PCR assays are flagellin [43 - 47] and $66 \mathrm{kDa}$ protein [41, 44, 48, 49] which were historically the first targets analyzed by PCR and most recently the gene encoding the Borrelia 16S rRNA [36, 43, 48 - 50]. As some plasmids may be present in more than a copy per Borrelia cell a plasmid target based PCR could be more sensitive. The "target imbalance" in Borrelia assays could be one of the multiple issues affecting Borrelia detection by PCR [37].

Overall, standardization is the major concern with respect to PCR for Borrelia detection.

PCR detection of Borrelia DNA does not enable to distinguish between dead or living microorganisms, because it is a poor indicator of the viability of the bacteria [51]. To this regard, quantitative analysis of flagellin B mRNA of Borrelia has been shown to correlate well with the culture results in Lyme disease, thus demonstrating the bacterial viability [51]. Although RNA analyses for Borrelia could be a surrogate biomarker for Borrelia active infection it is laborious and not suitable for routine analyses [37].

Recently, several CE-IVD PCR assays have been developed for Borrelia detection, among them: the EliGene ${ }^{\circledR}$ Borrelia kit (Elisabeth Pharmacon group, Czech Republic and UK); the Borrelia burgdorferi PCR kit (GeneProofa.s, Czech Republic), the real time PCR Borrelia burgdorferi sensu lato (Dynex, Czech Republic), the Borrelia burgdorferi s.l. kit (Biorn Diagnostics GmbH, Germany), the Borrelia Burgdorferi kit (Clonit S.r.l. , Italy), the BactoReal ${ }^{\circledR}$ Borrelia Burgdorferi sensu lato (Ingenetix, Austria) and the Diarella Borrelia real time PCR Kit (Gerbion, Germany) [4 - 10]. Most of them are qualitative real time PCR tests, multiplexing both an internal host control (human housekeeping gene) and the specific Borrelia target. Detection of DNA of Borrelia species pathogenic to human (B. afzelii, B. garinii, B. burgdorferi sensu stricto) has been guaranteed by amplifying flagellin gene [5 - 7], but also OspA [9]. Those commercial kits could be used for blood, additionally tests could be applied to cerebrospinal fluid and urine $[4-6,9,10]$, to ticks $[4,10]$ or ticks' suspension [6]. Sensitivities of those tests are highly variable and not conventionally described. Overall those commercial assays could have an impact on the reproducibility of PCR assays for Borrelia detection only because they decrease the variability in the reagent preparations and primer design. To this regard, the use of commercial kits represents a sort of harmonization in the assay preparation rather than standardization. There are no scientific publications comparing the performance of those commercial products with respect to serology, cultivation and in house PCR protocols in Lyme disease patients and controls. Clinical usefulness and added value to routine of those commercial assays should be confirmed/assessed by large validation studies with internal and external quality controls.

Overall, the scenario of PCR analyses for Lyme disease confirmation is wide and having reliable, reproducible tool standardization is of paramount importance in all the phases of the PCR process, starting from sample selection (e.g., type of sample and the required volume to be processed) as well as the pre-analytical phases such as the extraction procedures.

\section{INDIRECT METHODS- SEROLOGY}

Antibodies against Borrelia species are slow to develop, with IgM generally not being detectable for the first 1-2 weeks from the infection and IgG often not emerging for 4-6 weeks [52]. Moreover, there is evidence that some patients with solitary erythema migrans (EM) as their only manifestation may never seroconvert [52], particularly in Europe [53].

In Lyme disease the rate of seropositivity seems to correlate with the duration of symptoms before diagnosis [54] and duration of treatment not only at presentation, but also during follow-up, indicating that early antibiotic treatment may abrogate the development of seropositivity [52]. There is great variability in the specific antigens recognized by individual sera and the extent to which serum antibodies recognize homologous proteins from other pathogenic Borrelia species or even from heterologous strains of the same species $[52,55]$.

Both IgM and IgG Borrelia-specific antibodies may persist for years in some patients [1], which makes it impossible to distinguish between past and newly acquired infections based on seropositivity alone [52]. Seroprevalence indeed is of particular interest in endemic areas, showing in some European regions a gender and age trend [13, 56, 57].

In Europe [58], United States [59] and Canada a two tier testing serology is recommended for borreliosis 
assessment[1, 2, 60]. The first tier consists of a sensitive initial serological test or tests that detect class-specific antibodies (IgM and IgG, either together or separately). First-tier tests are enzyme immunoassays (EIAs) such as ELISAs or, rarely today, indirect immunofluorescence assays (IFAs) as they require a skilled microscopist and cannot be scored objectively. If the result of first-tier testing is negative, the serum is not tested further. If the result is positive or indeterminate (a value that is sometimes called 'borderline'), a second step should be performed [60]. The second tier determines the antigens recognized by the antibodies detected in the first step using separate $\operatorname{IgG}$ and IgM immunoblots.

General limitations in serological tests for Lyme borreliosis are related to detectability of antibodies, to differences in Borrelia genospecies and to the clinical spectra of the Lyme disease. It is well known indeed that two-tiered testing is insensitive in acute erythema migrans and may be negative in early neuroborreliosis $[1,2,52,60]$.

General drawbacks for two tier approaches are that the two-step procedure is complex, technically demanding and costly. Besides the technical aspects of the serological tests, Perronne [2] has reported on several other factors that could lead to seronegativity in confirmed cases of Lyme disease: among such factors are sequestration of antibodies in immune complexes, different species and subspecies of Borrelia distributed worldwide, as well as coinfections with other pathogens transmitted by the same vector.

Taken those observations it is manifest that new or better standardized immunological methods are needed to support the diagnosis of Lyme disease.

\subsection{ELISA}

Most commonly in ELISA, antigen mixtures composed of whole-cell sonicates of B. burgdorferi sensu lato are used as the source of antigen for the the individual or in combination detection of $\operatorname{IgG}$, IgM, or IgA antibodies. Usually those sonicates are derived from strain B31 [2], a specific strain of Borrelia burgdorferi sensu stricto, which is the only organism established to cause Lyme disease in North America [60]. Since in Europe and Asia Lyme disease also results from infection by Borrelia garinii or Borrelia afzelii, as well as by the recently described Borrelia spielmanii in Europe; diagnostic tests using antigens from B. burgdorferi sensu stricto will not necessarily perform well for infections carried by other genospecies, although some do [60].

The Vmp-like sequence expressed (VlsE) protein is a surface-exposed lipoprotein encoded by a linear plasmid of B. burgdorferi B31 and it has been found to be highly immunogenic [17]. In the last decade, an ELISA using only a single synthetic peptide derived from the VlsE sequence (IR6 or C6 peptide) as the source of antigen has become commercially available and is quite often used in the first step of the serological analyses. Both the single C6 peptide and whole VlsE assays have been approved as alternatives to whole-cell ELISAs as first-tier tests [60]. In addition, the Immunetics C6 test (Immunetics Inc, MA, USA) has recently been evaluated as an assay that could be used in place of both steps of two-tiered testing, that is, as a simple 'stand-alone' test [60]. C6- and VlsE-based assays have the additional feature of detecting antibodies to Eurasian genospecies of Borrelia (i.e. B. gariniiand B. azfelii) as well as B. burgdorferi sensu stricto [60]. Moreover, in a multiplex bead based assay for the detection of serum antibodies to Borrelia burgdorferi sensu lato it has recently been shown that VlsE IgG had the highest diagnostic value even in patients with neuroborreliosis [61].

\subsection{Immunoblots}

Regarding immunoblots, recommendations have been published by Centers for Disease Control and Prevention (CDC) on the number and types of $\operatorname{IgM}$ and $\operatorname{IgG}$ bands in order to consider immunoblot results as positive [59]. However, those rules could be applied in the US, but not to patients infected in Europe since immune response of European patients is restricted to a narrower spectrum of Borrelia proteins, compared with that shown by American patients [3].

Consequently, the existence of at least 3 pathogenic species requires species-specific interpretation rules [52].

Traditional blots are hard to standardize, as they are only semi-quantitative and reading them involves often subjective judgment about the significance of weak bands [60].

\section{OUR EXPERIENCE}

As an explicative example of the assumption that both PCR analyses on DNA and serology do not allow distinguishing between active and inactive Borrelia, here we report our (unpublished) data referred to serological and PCR analysis of healthy volunteers living in an endemic area. All the participants have lived in villages of the 
transborder rural area between Italy and Slovenia and all of them reported having been bitten by ticks during their life. All the participants in the study completed a questionnaire designed by the author of the presented study, and had both serologic tests performed using immunoenzymatic test VlsE ELISA, by which the level of Borrelia burgdorferi IgM and IgG class antibodies were determined in blood serum as well as two PCR analyses on blood extracts targeting a fragment of flagellin gene and $66 \mathrm{kDa}$ protein [44]. Blood and data were collected over May 2005. Fifty-two people participated in this survey (median age 47 years), 31 of them were males and 21 females. Of those, 8 participants (5 males and 3 females) had had Lyme disease in the past. Among the requested information, participants reported the date of their last tick's bite, the therapy followed for concurrent chronic diseases, their job and if they had taken antibiotics in the month before blood and data collection. Results and participants' characteristics are reported in (Table 1). Overall there are no differences in the antibody profiles between volunteers with previous Lyme disease or without. Both IgG and IgM positivity and detection of Borrelia by PCR were not related to previous antibiotic treatment ( $p=1.0$ for both) as well as to concomitant chronic disease $(p=1.0)$. IgG and IgM resulted simultaneously positive only in one participant, a 67-year-old man who didn't have Lyme disease previously. The only volunteer who had positive borrelia detection by PCR (flagellin) was a 26-year-old man who reported Lyme disease (erythema migrans) 1 month before. In that person IgG and IgM profiles were negative. All volunteers with positive IgG or IgM underwent dermatological examination (PIC Interreg IIIA Italy-Slovenia 2000-2006 Project No: AAFVG332366). None of the seropositive volunteers had signs of Lyme disease.

Table 1. Data on participants.

\begin{tabular}{|c|c|c|c|}
\hline & With previous Lyme disease (8) & Without previous Lyme disease (44) & $\boldsymbol{p}$ \\
\hline Gender & 5 & 26 & 0.9 \\
Female & 3 & 18 & \\
Male & 4 & 7 & 0.2 \\
\hline IgG positive & 1 & 0 & 0.6 \\
\hline IgM positive & 1 & 0 & 0.2 \\
\hline PCR flagellin positive & 0 & 26 & 1.0 \\
\hline PCR 66 kDa positive & 3 & 6 & 0.5 \\
Job & 3 & & \\
Clerical or educational workers & 2 & & \\
Retirees & & & \\
Students & & & \\
\end{tabular}

Overall both $\mathrm{IgG}$ and IgM positivity, as well as PCR, were not associated with any of the requested information although $\mathrm{IgG}$ positivity tends to prefer older volunteers $(p=0.08)$. IgG positivity did not result significantly different among jobs, but IgM ( $p=0.04)$ was detected in 0 out 29 workers, in 1 out of 8 students and 3 out of 14 pensioners.

Our data agree with the scientific community $[1,60]$ regarding the usefulness of both PCR and serologic exams for Borrelia detection in healthy people.

\section{CONCLUSION}

As a general consensus diagnostic investigation for Lyme disease should be restricted only to those people who show signs and/or symptoms of Lyme disease. In endemic area serologic positivity could be a quite a frequent event because of the exposition to Borrelia. Diagnostic tests are of clinical value only if they are used properly in patients with objective signs of Lyme disease and with a history of potential exposure to infected vector ticks [60].

\section{CONFLICT OF INTEREST}

The author confirms that this article content has no conflict of interest.

\section{ACKNOWLEDGEMENTS}

The author is grateful to Dr Valentina Melita for the language revision of the manuscript and to Dr Ermanno Nardon for his critical suggestions.

\section{REFERENCES}

[1] Aguero-Rosenfeld ME, Wormser GP. Lyme disease: diagnostic issues and controversies. Expert Rev Mol Diagn 2015; 15(1): 1-4. [http://dx.doi.org/10.1586/14737159.2015.989837] [PMID: 25482091] 
[2] Perronne C. Lyme and associated tick-borne diseases: global challenges in the context of a public health threat. Front Cell Infect Microbiol 2014; $4: 74$.

[http://dx.doi.org/10.3389/fcimb.2014.00074] [PMID: 24918091]

[3] Wilske B, Fingerle V, Schulte-Spechtel U. Microbiological and serological diagnosis of Lyme borreliosis. FEMS Immunol Med Microbiol 2007; 49(1): 13-21. [http://dx.doi.org/10.1111/j.1574-695X.2006.00139.x] [PMID: 17266710]

[4] GeneProof Borrelia burgdorferi PCR Kit. Available from: http://www.geneproof.com/products/human-microbiologicaldiagnostics/geneproof-borrelia-burgdorferi-pcr-kit

[5] EliGene ${ }^{\circledR}$ Borrelia RT. Available from: http://www.eligene.com/borrelia.htm

[6] Borrelia Burgdorferi s.l. Available from: http://www.bioron.de/index.php/en/products/pathogen/realline-kits- for-infectionaldiagnostics/realline-borrelia/

[7] Kit Borrelia Burgdorferi. Available from: http://www.clonit.it/en-GB/products/fast-pcr-reagents/kit-1/

[8] Real time PCR Borrelia burgdorferi sensu lato. Available from: https://http://www.szabo-scandic.com/fileadmin/content/docs/Borrelia burgdorferi_Sensu_Lato_ENG_2012.pdf

[9] BactoReal ${ }^{\circledR}$ Borrelia Burgdorferi sensu lato. Available from: http://www.ingenetix.com/wp-content/uploads/2011/07/BactoReal_Borrelia_ burgdorferi_RTGM500_ingenetix_Description_v1-1e1.pdf

[10] Diarella Borrelia real time PCR Kit. Available from: http://www.gerbion.de/en/products.php?radio=1.1.2. - liste

[11] Stricker RB, Burrascano J, Winger E. Longterm decrease in the CD57 lymphocyte subset in a patient with chronic Lyme disease. Ann Agric Environ Med 2002; 9(1): 111-3. [PMID: 12088407]

[12] Stricker RB, Winger EE. Decreased CD57 lymphocyte subset in patients with chronic Lyme disease. Immunol Lett 2001; $76(1)$ : 43-8. [http://dx.doi.org/10.1016/S0165-2478(00)00316-3] [PMID: 11222912]

[13] Wilking H, Fingerle V, Klier C, Thamm M, Stark K. Antibodies against Borrelia burgdorferi sensu lato among Adults, Germany, $2008-2011$. Emerg Infect Dis 2015; 21(1): 107-10. [http://dx.doi.org/10.3201/eid2101.140009] [PMID: 25531140]

[14] Hytönen J, Kortela E, Waris M, Puustinen J, Salo J, Oksi J. CXCL13 and neopterin concentrations in cerebrospinal fluid of patients with Lyme neuroborreliosis and other diseases that cause neuroinflammation. J Neuroinflammation 2014; $11: 103$.

[http://dx.doi.org/10.1186/1742-2094-11-103] [PMID: 24920219]

[15] Moniuszko A, Czupryna P, Pancewicz S, et al. Evaluation of CXCL8, CXCL10, CXCL11, CXCL12 and CXCL13 in serum and cerebrospinal fluid of patients with neuroborreliosis. Immunol Lett 2014; 157(1-2): 45-50. [http://dx.doi.org/10.1016/j.imlet.2013.11.002] [PMID: 24239846]

[16] Bremell D, Mattsson N, Edsbagge M, et al. Cerebrospinal fluid CXCL13 in Lyme neuroborreliosis and asymptomatic HIV infection. BMC Neurol 2013; 13: 2 . [http://dx.doi.org/10.1186/1471-2377-13-2] [PMID: 23294475]

[17] Aguero-Rosenfeld ME, Wang G, Schwartz I, Wormser GP. Diagnosis of lyme borreliosis. Clin Microbiol Rev 2005; 18(3): 484-509. [http://dx.doi.org/10.1128/CMR.18.3.484-509.2005] [PMID: 16020686]

[18] Veinović G, Cerar T, Strle F, Ružić-Sabljić E. Influence of MKP medium stored for prolonged periods on growth and morphology of Borrelia afzelii, Borrelia garinii, and Borrelia burgdorferi sensu stricto. APMIS 2014; 122(3): 230-5. [http://dx.doi.org/10.1111/apm.12129] [PMID: 23758221]

[19] Cerar T, Ogrinc K, Cimperman J, Lotric-Furlan S, Strle F, Ruzić-Sabljić E. Validation of cultivation and PCR methods for diagnosis of Lyme neuroborreliosis. J Clin Microbiol 2008; 46(10): 3375-9. [http://dx.doi.org/10.1128/JCM.00410-08] [PMID: 18716226]

[20] MacDonald AB. Borrelia burgdorferi tissue morphologies and imaging methodologies. Eur J Clin Microbiol Infect Dis 2013 ; 32 (8): 1077-82. [http://dx.doi.org/10.1007/s10096-013-1853-5] [PMID: 23479042]

[21] Wanyura H, Wagner T, Samolczyk-Wanyura D. Borrelia burgdorferi-a potentially aetiological factor in TMJ disorders? Preliminary report. J Craniomaxillofac Surg 2008; 36(1): 28-33. [http://dx.doi.org/10.1016/j.jcms.2007.05.007] [PMID: 18023198]

[22] Eisendle K, Grabner T, Zelger B. Focus floating microscopy: “gold standard” for cutaneous borreliosis? Am J Clin Pathol 2007; 127(2): $213-22$ [http://dx.doi.org/10.1309/3369XXFPEQUNEP5C] [PMID: 17210530]

[23] White KP, Barry CI, Patterson JW. Focus-floating microscopy for detecting borrelia species in tissue sections: back to basics. Arch Dermatol 2008; 144(5): 662-3. [http://dx.doi.org/10.1001/archderm.144.5.662] [PMID: 18490595]

[24] Derler AM, Eisendle K, Baltaci M, Obermoser G, Zelger B. High prevalence of 'Borrelia-like' organisms in skin biopsies of sarcoidosis patients from Western Austria. J Cutan Pathol 2009; 36(12): 1262-8. [http://dx.doi.org/10.1111/j.1600-0560.2009.01271.x] [PMID: 19469874] 
[25] Eisendle K, Baltaci M, Kutzner H, Zelger B. Detection of spirochaetal microorganisms by focus floating microscopy in necrobiosis lipoidica in patients from central Europe. Histopathology 2008; 52(7): 877-84. [http://dx.doi.org/10.1111/j.1365-2559.2008.03051.x] [PMID: 18462358]

[26] Eisendle K, Grabner T, Kutzner H, Zelger B. Possible role of Borrelia burgdorferi sensu lato infection in lichen sclerosus. Arch Dermatol 2008; 144(5): 591-8. [http://dx.doi.org/10.1001/archderm.144.5.591] [PMID: 18490585]

[27] Eisendle K, Grabner T, Zelger B. Morphoea: a manifestation of infection with Borrelia species? Br J Dermatol 2007; 157(6): 1189-98. [http://dx.doi.org/10.1111/j.1365-2133.2007.08235.x] [PMID: 17941947]

[28] Müller KE. Damage of collagen and elastic fibres by borrelia burgdorferi - known and new clinical and histopathological aspects. Open Neurol J 2012; 6: 179-86.

[http://dx.doi.org/10.2174/1874205X01206010179] [PMID: 23986790]

[29] Santos M, Ribeiro-Rodrigues R, Talhari C, Ferreira LC, Zelger B, Talhari S. Presence of Borrelia burgdorferi "Sensu Lato" in patients with morphea from the Amazonic region in Brazil. Int J Dermatol 2011; 50(11): 1373-8. [http://dx.doi.org/10.1111/j.1365-4632.2011.05081.x] [PMID: 22004491]

[30] Talhari S, de Souza Santos MN, Talhari C, et al. Borrelia Burgdorferi "sensu lato" in Brazil: Occurrence confirmed by immunohistochemistry and focus floating microscopy. Acta Trop 2010; 115(3): 200-4. [http://dx.doi.org/10.1016/j.actatropica.2010.02.017] [PMID: 20211144]

[31] Verberkt RM, Janssen M, Wesseling J. A boy with a tight skin: Borrelia-associated early-onset morphea. Clin Exp Rheumatol 2014; 32(1): 121-2.

[PMID: 24093617]

[32] Zelger B, Eisendle K, Mensing C, Zelger B. Detection of spirochetal micro-organisms by focus-floating microscopy in necrobiotic xanthogranuloma. J Am Acad Dermatol 2007; 57(6): 1026-30. [http://dx.doi.org/10.1016/j.jaad.2007.05.016] [PMID: 18021850]

[33] Ziemer M, Eisendle K, Müller H, Zelger B. Lymphocytic infiltration of the skin (Jessner-Kanof) but not reticular erythematous mucinosis occasionally represents clinical manifestations of Borrelia-associated pseudolymphoma. Br J Dermatol 2009; 161(3): 583-90. [http://dx.doi.org/10.1111/j.1365-2133.2009.09279.x] [PMID: 19486001]

[34] Ziemer M, Eisendle K, Zelger B. New concepts on erythema annulare centrifugum: a clinical reaction pattern that does not represent a specific clinicopathological entity. Br J Dermatol 2009; 160(1): 119-26. [http://dx.doi.org/10.1111/j.1365-2133.2008.08803.x] [PMID: 18721189]

[35] Ziemer M, Grabner T, Eisendle K, Baltaci M, Zelger B. Granuloma annulare--a manifestation of infection with Borrelia? J Cutan Pathol 2008; 35(11): 1050-7. [http://dx.doi.org/10.1111/j.1600-0560.2007.00977.x] [PMID: 18616764]

[36] O'Rourke M, Traweger A, Lusa L, et al. Quantitative detection of Borrelia burgdorferi sensu lato in erythema migrans skin lesions using internally controlled duplex real time PCR. PLoS One 2013; 8(5): e63968. [http://dx.doi.org/10.1371/journal.pone.0063968] [PMID: 23696863]

[37] Nolte O. Nucleic acid amplification based diagnostic of lyme (neuro-)borreliosis - lost in the jungle of methods, targets, and assays? Open Neurol J 2012; 6: 129-39.

[http://dx.doi.org/10.2174/1874205X01206010129] [PMID: 23230454]

[38] Dunaj J, Moniuszko A, Zajkowska J, Pancewicz S. The role of PCR in diagnostics of Lyme borreliosis. Przegl Epidemiol 2013; 67(1): 35-39, 119-123.

[PMID: 23745373]

[39] Floris R, Menardi G, Bressan R, et al. Evaluation of a genotyping method based on the ospA gene to detect Borrelia burgdorferi sensu lato in multiple samples of lyme borreliosis patients. New Microbiol 2007; 30(4): 399-410. [PMID: 18080675]

[40] Gooskens J, Templeton KE, Claas EC, van Dam AP. Evaluation of an internally controlled real-time PCR targeting the ospA gene for detection of Borrelia burgdorferi sensu lato DNA in cerebrospinal fluid. Clin Microbiol Infect 2006; 12(9): 894-900. [http://dx.doi.org/10.1111/j.1469-0691.2006.01509.x] [PMID: 16882295]

[41] Priem S, Burmester GR, Kamradt T, Wolbart K, Rittig MG, Krause A. Detection of Borrelia burgdorferi by polymerase chain reaction in synovial membrane, but not in synovial fluid from patients with persisting Lyme arthritis after antibiotic therapy. Ann Rheum Dis 1998; 57(2): 118-21.

[http://dx.doi.org/10.1136/ard.57.2.118] [PMID: 9613343]

[42] Livey I, O’Rourke M, Traweger A, et al. A new approach to a Lyme disease vaccine. Clin Infect Dis 2011; 52(Suppl. 3): s266-70. [http://dx.doi.org/10.1093/cid/ciq118] [PMID: 21217174]

[43] de Leeuw BH, Maraha B, Hollemans L, et al. Evaluation of Borrelia real time PCR DNA targeting OspA, FlaB and 5S-23S IGS and Borrelia 16S rRNA RT-qPCR. J Microbiol Methods 2014; 107: 41-6. [http://dx.doi.org/10.1016/j.mimet.2014.09.001] [PMID: 25218111]

[44] Pauluzzi P, Bonin S, Gonzalez Inchaurraga MA, Stanta G, Trevisan G. Detection of spirochaetal DNA simultaneously in skin biopsies, 
peripheral blood and urine from patients with erythema migrans. Acta Derm Venereol 2004; 84(2): 106-10. [http://dx.doi.org/10.1080/00015550310006815] [PMID: 15206688]

[45] Cerar T, Ruzić-Sabljić E, Glinsek U, Zore A, Strle F. Comparison of PCR methods and culture for the detection of Borrelia spp. in patients with erythema migrans. Clin Microbiol Infect 2008; 14(7): 653-8. [http://dx.doi.org/10.1111/j.1469-0691.2008.02013.x] [PMID: 18558937]

[46] Jenkins A, Hvidsten D, Matussek A, Lindgren PE, Stuen S, Kristiansen BE. Borrelia burgdorferi sensu lato in Ixodes ricinus ticks from Norway: evaluation of a PCR test targeting the chromosomal flaB gene. Exp Appl Acarol 2012; 58(4): 431-9. [http://dx.doi.org/10.1007/s10493-012-9585-2] [PMID: 22684812]

[47] Mantovani E, Marangoni RG, Gauditano G, Bonoldi VL, Yoshinari NH. Amplification of the flgE gene provides evidence for the existence of a Brazilian borreliosis. Rev Inst Med Trop Sao Paulo 2012; 54(3): 153-7. [http://dx.doi.org/10.1590/S0036-46652012000300007] [PMID: 22634887]

[48] Pintore MD, Ceballos L, Iulini B, et al. Detection of invasive Borrelia Burgdorferi strains in North-Eastern Piedmont. In: Italy: Zoonoses Public Health 2014

[49] Santino I, Berlutti F, Pantanella F, Sessa R, del Piano M. Detection of Borrelia burgdorferi sensu lato DNA by PCR in serum of patients with clinical symptoms of Lyme borreliosis. FEMS Microbiol Lett 2008; 283(1): 30-5. [http://dx.doi.org/10.1111/j.1574-6968.2008.01134.x] [PMID: 18384365]

[50] Ornstein K, Barbour AG. A reverse transcriptase-polymerase chain reaction assay of Borrelia burgdorferi 16S rRNA for highly sensitive quantification of pathogen load in a vector. Vector Borne Zoonotic Dis 2006; 6(1): 103-12. [http://dx.doi.org/10.1089/vbz.2006.6.103] [PMID: 16584333]

[51] Borchers AT, Keen CL, Huntley AC, Gershwin ME. Lyme disease: a rigorous review of diagnostic criteria and treatment. J Autoimmun 2014. [PMID: 25451629]

[52] Li X, McHugh GA, Damle N, Sikand VK, Glickstein L, Steere AC. Burden and viability of Borrelia burgdorferi in skin and joints of patients with erythema migrans or lyme arthritis. Arthritis Rheum 2011; 63(8): 2238-47. [http://dx.doi.org/10.1002/art.30384] [PMID: 21590753]

[53] EUCLAB-European Concerted Action on Lyme Borreliosis. Available from: http://www.eucalb.com

[54] Centers for Disease Control and Prevention (CDC)-Lyme Disease. Available from: http://www.cdc.gov/lyme/

[55] Johnson BJ. Laboratory diagnostic testing for Borrelia Burgdorferi infection. In: Halperin JJ, Ed. Lyme Disease: An evidence-based approach. CAB International 2011; pp. 73-88. [http://dx.doi.org/10.1079/9781845938048.0073]

[56] Glatz M, Golestani M, Kerl H, Müllegger RR. Clinical relevance of different IgG and IgM serum antibody responses to Borrelia burgdorferi after antibiotic therapy for erythema migrans: long-term follow-up study of 113 patients. Arch Dermatol 2006; 142(7): 862-8. [http://dx.doi.org/10.1001/archderm.142.7.862] [PMID: 16847202]

[57] Cerar T, Ogrinc K, Strle F, Ruzić-Sabljić E. Humoral immune responses in patients with Lyme neuroborreliosis. Clin Vaccine Immunol 2010; 17(4): $645-50$ [http://dx.doi.org/10.1128/CVI.00341-09] [PMID: 20164248]

[58] Goettner G, Schulte-Spechtel U, Hillermann R, Liegl G, Wilske B, Fingerle V. Improvement of Lyme borreliosis serodiagnosis by a newly developed recombinant immunoglobulin $\mathrm{G}$ (IgG) and IgM line immunoblot assay and addition of VlsE and DbpA homologues. J Clin Microbiol 2005; 43(8): 3602-9. [http://dx.doi.org/10.1128/JCM.43.8.3602-3609.2005] [PMID: 16081885]

[59] Hjetland R, Nilsen RM, Grude N, Ulvestad E. Seroprevalence of antibodies to Borrelia burgdorferi sensu lato in healthy adults from western Norway: risk factors and methodological aspects. APMIS 2014; 122(11): 1114-24. [PMID: 24730472]

[60] Pańczuk A, Kozioł-Montewka M, Tokarska-Rodak M. Exposure to ticks and seroprevalence of Borrelia burgdorferi among a healthy young population living in the area of southern Podlasie, Poland. Ann Agric Environ Med 2014; 21(3): 512-7. [http://dx.doi.org/10.5604/12321966.1120593] [PMID: 25292120]

[61] Dessau RB, Møller JK, Kolmos B, Henningsson AJ. Multiplex assay (Mikrogen recomBead) for detection of serum IgG and IgM antibodies to 13 recombinant antigens of Borrelia burgdorferi sensu lato in patients with neuroborreliosis: the more the better? J Med Microbiol 2015; 64(Pt 3): 224-31.

[http://dx.doi.org/10.1099/jmm.0.000009] [PMID: 25587083]

Received: October 22, $2015 \quad$ Revised: December 16, $2015 \quad$ Accepted: December 16, 2015

(C) Serena Bonin; Licensee Bentham Open.

This is an open access article licensed under the terms of the Creative Commons Attribution-Non-Commercial 4.0 International Public License (CC BY-NC 4.0) (https://creativecommons.org/licenses/by-nc/4.0/legalcode), which permits unrestricted, non-commercial use, distribution and reproduction in any medium, provided the work is properly cited. 